\title{
Endoscopic ultrasound-guided, through-the-needle forceps biopsy in the assessment of an incidental large pancreatic cystic lesion with prior inconclusive fine-needle aspiration
}
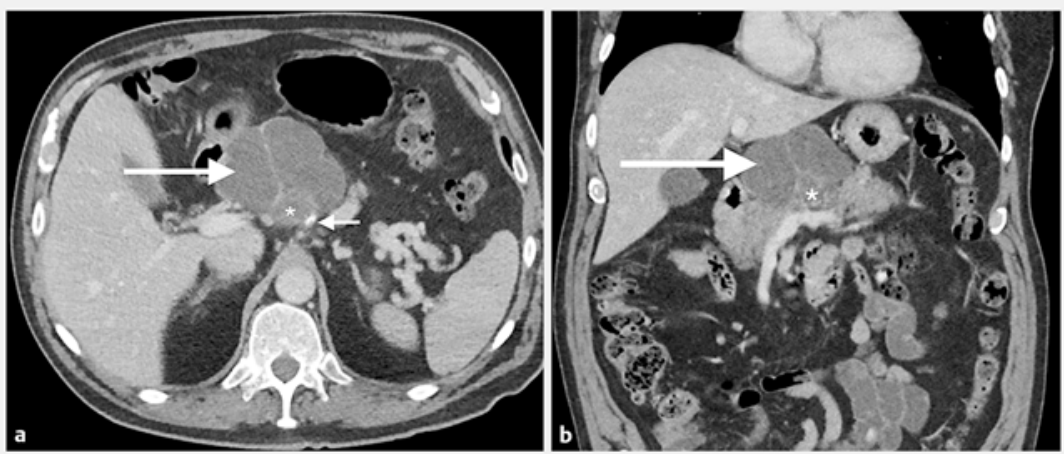

- Fig. 1 Cystic pancreatic neck lesion in a 68-year-old man. a Axial contrast-enhanced computed tomography (CT) in the portal venous phase shows an exophytic multilocular cystic lesion arising from the genu of the pancreas (long arrow) with a small solid $\left({ }^{*}\right)$ and calcific (short arrow) component posteriorly. b Coronal contrast-enhanced CT in the portal venous phase shows the pancreas (arrow) with a small solid component inferiorly $\left({ }^{*}\right)$. The pancreatic parenchyma is otherwise normal.

A 68-year-old man underwent endoscopic ultrasound (EUS) and fine-needle aspiration of a large cystic lesion of the pancreatic neck seen incidentally on computed tomography (CT). CT demonstrated a nonenhancing, exophytic, multilocular cystic mass, measuring $82 \times 72$ mm ( Fig. 1, \Video 1). A mural calcific focus was noted posteroinferiorly and a more solid component posteriorly. The CT density averaged $19 \mathrm{HU}$ for the cystic component and $40 \mathrm{HU}$ for the solid component.

EUS showed a mixed solid/cystic-appearing lesion without mural nodules. The cystic component contained multiple mobile ball-like structures ( $\mathbf{F i g}$. 2 ) and the solid component appeared to be hypoechoic and heterogeneous. No infiltration into the surrounding tissue or pancreatic duct communication was identified and the pancreas was otherwise unremarkable. In addition, no lymphadenopathy was present.

EUS-guided transgastric cyst aspiration was performed using a 19-gauge needle, and $8 \mathrm{ml}$ of an opaque, turbid fluid was sent for cytological examination. Amylase and carcinoembryonic antigen
(CEA) levels did not contribute to the diagnosis and the results of cytology investigation were inconclusive, revealing only cholesterol crystals, lipoid droplets, and scant leukocytes.

A repeat EUS was undertaken to biopsy the cyst wall with dedicated throughthe-needle Moray micro forceps (US Endoscopy, Mentor, Ohio, USA) (> Fig.3).

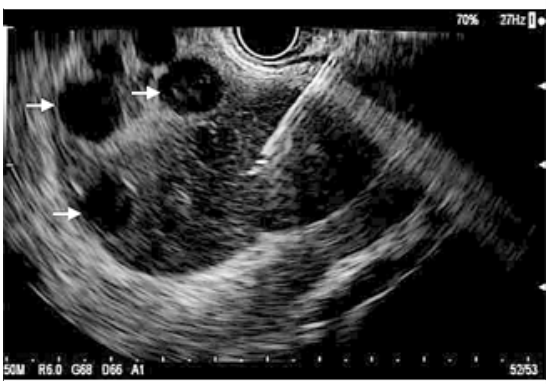

- Fig. 2 Floating ball-like structures (arrows), each approximately $1 \mathrm{~cm}$ in size, within the liquid-filled cyst compartment. The tip of the 19-gauge needle is visible located within the cyst prior to introduction of the micro forceps (see $>$ Video 1 ).

The forceps were passed through a 19-gauge needle and allowed precise and targeted sampling of the cyst wall ( $\triangleright$ Fig.2). In a second pass, the solidappearing component was targeted and $5 \mathrm{ml}$ of a thick, brown fluid were aspirated.

Histological assessment revealed fragments of keratinizing squamous epithe-

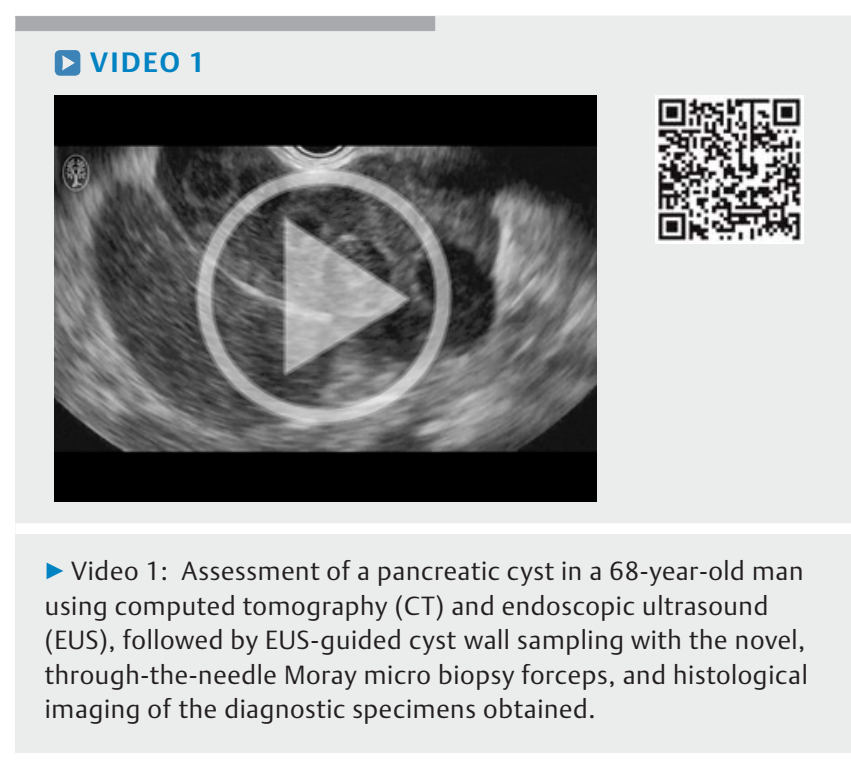




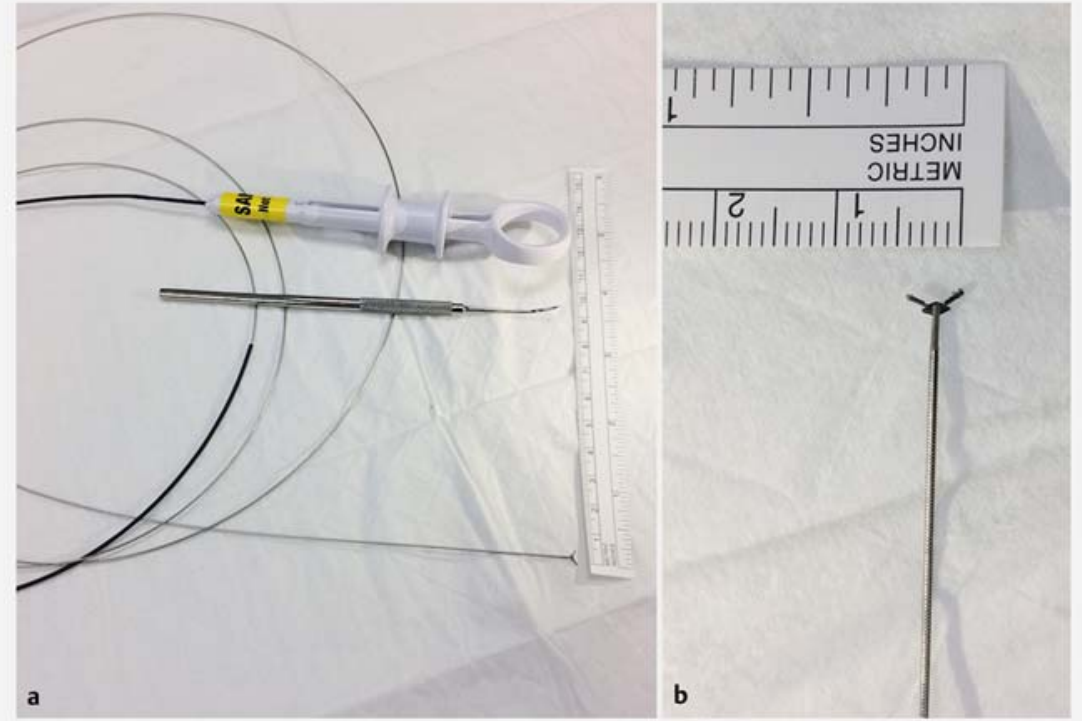

Fig. 3 Moray micro forceps. a The device is shown with the handle and sheath, and includes an extraction pick to aid retrieval from the jaw cup. $\mathbf{b}$ The serrated jaw opening width of $4.3 \mathrm{~mm}$.

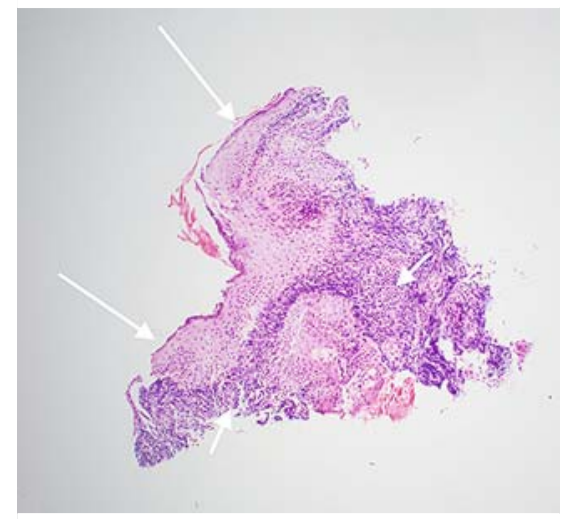

- Fig. 4 Histological appearance of the cyst wall specimen obtained using Moray micro forceps. Keratinizing stratified squamous epithelium (long arrows) with subepithelial dense lymphoid tissue (short arrows) can be seen. (Magnification $\times 100$; hematoxylin and eosin stain.) All cyst wall samples had similar characteristics. lium with a subepithelial lymphoid infiltrate ( $>$ Fig.4). Dense keratin was present on the surface. No goblet cells were seen. The findings were diagnostic for a benign lymphoepithelial cyst [1-3]. Surveillance is not required for this, and surgery is only considered in symptomatic individuals $[4,5]$. The patient could therefore be discharged.

The novel through-the-needle micro forceps were easy to use and allowed precise EUS-guided sampling of the cyst wall.

Endoscopy_UCTN_Code_TTT_1AS_2AF

\section{Competing interests}

The Moray micro forceps used in this specific case was a free sample supplied by US Endoscopy, Mentor, Ohio, USA and Device Technologies, Belrose, New South Wales, Australia.
The Authors

Alexander Huelsen ${ }^{1,2}$, Caroline Cooper ${ }^{2,3}$, Nivene Saad ${ }^{2,4}$, Saurabh Gupta ${ }^{1,2}$

1 Department of Gastroenterology and Hepatology, Princess Alexandra Hospital, Brisbane, Queensland, Australia

2 School of Medicine, University of Queensland, Brisbane, Queensland, Australia

3 Department of Anatomical Pathology, Princess Alexandra Hospital, Brisbane, Queensland, Australia

4 Department of Radiology, Princess Alexandra Hospital, Brisbane, Queensland, Australia

\section{Corresponding author}

\section{Alexander Huelsen, MD}

Department of Gastroenterology and Hepatology, Princess Alexandra Hospital, 199 Ipswich Road, Woolloongabba, Queensland 4102, Brisbane, Australia Fax: +61-7-31765111

Alexander.Huelsen-Katz@health.qld.gov.au

\section{Acknowledgment}

We would like to acknowledge US Endoscopy and Device Technologies Australia for the free supply of the Moray micro forceps used in this specific case.

\section{References}

[1] Mege D, Gregoire E, Barbier L et al. Lymphoepithelial cyst of the pancreas: an analysis of 117 patients. Pancreas 2014; 43: 987 995

[2] Adsay NV, Hasteh F, Cheng JD et al. Lymphoepithelial cysts of the pancreas: a report of 12 cases and a review of the literature. Mod Pathol 2002; 15: 492 - 501

[3] Matsubayashi H, Aikawa Y, Sugiura T et al. Pancreatic lymphoepithelial cyst showing multiple floating ball-like appearances. J Gastrointestin Liver Dis 2016; 25: 239-242

[4] Yanagimoto H, Satoi S, Toyokawa H et al. Laparoscopic distal pancreatectomy for a pancreatic lymphoepithelial cyst: case report and review of literature. JOP 2013; 14 : 664-668

[5] Dalal KS, DeWitt JM, Sherman S et al. Endoscopic ultrasound characteristics of pancreatic lymphoepithelial cysts: A case series from a large referral center. Endosc Ultrasound 2016; 5: $248-253$

\section{Bibliography}

DOI http://dx.doi.org/10.1055/s-0043-100217

Endoscopy 2017; 49: E109-E110

(c) Georg Thieme Verlag KG

Stuttgart · New York

ISSN 0013-726X 